\title{
Music Educational Therapy and the Figurenotes Music Pedagogical Approach for Young Children with Special Needs
}

\author{
Liza Lee, Hsiao-Fang Lin * \\ Department and Graduate Institute of Early Childhood Development and Education, Chaoyang University of Technology, Taiwan
}

Received March 17, 2020; Revised April 27, 2020; Accepted May 20, 2020

Copyright $(2020$ by authors, all rights reserved. Authors agree that this article remains permanently open access under the terms of the Creative Commons Attribution License 4.0 International License

\begin{abstract}
This study used the Figurenotes music pedagogical approach, combined with music education therapy strategies developed by Lee (2012), to deliver a specially designed music therapy course to children with special needs and determine how it might engage these students and positively influence their learning skills through the utilization of homemade elements, homemade instruments, teaching aids, and multisensory instruments. This study took place in a nonprofit, early-treatment institution in central Taiwan, and the participants were 56 young children with special needs aged 1-6 years. The research data were primarily obtained from a qualitative narrative, supplemented with quantitative data. The qualitative data included the basic information of the children and the observation record of their target ability, whereas the quantitative data were scored using a 5-point Likert scale. The findings revealed that most children took the initiative to participate in the activities, and the growth curve during this segment of instruction exhibited a steady upward trend. In summary, the use of Figurenotes as the core device demonstrated a significant and positive effect as a therapeutic device for children with special needs.
\end{abstract}

Keywords Figurenotes Music Pedagogical Approach, Young Children with Special Needs, Music Education Therapy, Special Music Education, Teaching Praxis

\section{Introduction}

Music has been used as a healing method since ancient times. In modern times, scholars have conducted systematic, in-depth research on the physical and mental healing capabilities of music. The International Society for Music Education and the Commission of Music in Special Education, Music Therapy, \& Music Medicine proposed that music therapy is not only a tool but also a theoretical and practical system that has achieved global recognition [1]. According to the definition provided by the World Federation of Music Therapy (WFMT), music therapy is the use of music or elements in music as an intervention method in fields such as medical treatment and education. It promotes the quality of life of individuals, groups, families, and even communities, and it improves their physical, social, interpersonal emotional, intellectual, and spiritual well-being [2]. Theoretical and practical research on music therapy has many limitations and shortcomings, mainly in two aspects. First, music therapy must be provided by a musician, music teacher, or music major; only licensed therapists or so-called "music-savvy people" can offer it [1]. However, anyone can be a musician. Even people without hearing can grasp natural rhythms and perform rhythmic activities. The essence of music is its rhythmic nature, so anyone can be "a person who knows music," meaning that anyone can implement music therapy, as long as he or she is trained in a particular theory and operation method. The second short coming is the belief that the sole purpose of music therapy is treatment of an underlying problem. Undeniably, music therapy has a mainly therapeutic purpose, but it must also be made clear that music therapy is different from medical therapy. If medical therapy is physiologically invasive, then music therapy is categorized as noninvasive psychological therapy [2]. This is the core concept of Music Education Therapy (MET) [1]. Psychotherapy must have initially or primarily psychological meaning. Therefore, music therapy does not concern treatment as much as it does cultivation of the psychological function of patients and the enhancement of their mental health.

Music therapy has been conceptually operationally applied in the field of education, giving rise to the concept of "therapeutic education." This distinction separates 
music therapy from music education. As mentioned, music actually has a healing effect through education. Therefore, it is "education" before "therapy." Moreover, music does not affect the function of "education" for patients, even if it does not have the effect of "therapy," but if practitioners only focus on "therapy" and ignore "education," then they may not achieve both [1]. In other words, music therapy should prompt patients to change their cognitive models, self-concepts, interpersonal relationships, and spiritual pursuits, which are educational functions. In summary of the findings of previous related research, the positive effects of music on children with special needs are as follows: 1 . Promotes communication and expression: Storr [3] believes that music is a means of communication and self-expression. For children with severe disabilities in particular, music can be one of the few means of interaction with others; 2. Promotes social opportunities: [4] The incorporation of music can help children confirm their sense of connection to their environments and others. People with physical and mental disabilities can share with each other by taking turns playing percussion instruments; 3 . Establishes confidence: Children with special needs can feel satisfied and have rewarding experiences while participating in music activities designed to increase their self-confidence[5];4.Enhances the experience of music appreciation: Thompson [6] believed that music educators could benefit children with physical and mental disabilities by interacting with them to enable them to experience music and develop musical skills; 5. Promotes movement development: Music activities are a combination of music and activities. Music can promote the development of consciousness, help children with disabilities to concentrate, and improve coordination and physical functions [7].

Special education is highly developed in the Finnish educational system. The Resonaari Special Music Centre in Helsinki, Finland has a music school for people with special needs. Figurenotes is a music pedagogical approach proposed by Finnish music educator Kaarlo Uusitalo in 1996, mainly to create opportunities for people with special needs to participate in music activities [8]. In Resonaari, all learning courses are adjustable and flexible according to different and individual needs $[9,10,11]$. The institution also hosts research and development work, employs staff to produce material and organize courses, provides complementary education, and maintains a network for professionals, associations, polytechnics, and universities in Finland and abroad [12]. The notation information is marked through colors and shapes. Figurenotes uses colors and shapes familiar to the child to replace the standard notation symbols to allow them to play music more easily. Additionally, Figurenotes uses textbooks and teaching aids that correlate to the Figurenotes colors and shapes and employs a self-made instrument representing the seven colors (red, brown, gray, blue, black, yellow, and green) of the note scale, so that the child can play an instrument in the course. The goals of this innovative teaching model are to improve the child's reaction and concentration and to enhance all aspects of his or her performance ability. [7] believes that teachers must modify and adjust their teaching methods when addressing the needs of physically and mentally disabled individuals so that students can still have musical experiences even when they are physically and mentally disabled. The purpose of this teaching method is not only for children to be able to play a complete song but also for them to learn in the process.

\section{Materials and Methods}

The study participants were young children with special needs. Before teaching, the Individualized Support Program and observation records of each child were checked in advance to understand the physical and mental development of each child. This study employed the MET and Figurenotes teaching methods, combining two pedagogical approach theories and models to guide the children's physical and mental development with a rich curriculum design. The intent was to cultivate the tacit understanding of the teaching team, improve the music ability and teaching practice experience of the teaching staff, and make more comprehensive the skills that the teaching staff have as professional early childhood educators.

\subsection{Data Source and Sample}

This study took place at a nonprofit, early-treatment institution in central Taiwan, and its sample included 56 young children with special needs aged from 1-6 years old. The students were separated into five daycare classes. The five classes were known as the Rainbow class(13 children), Sweet class (13 children), Beibei class (6 children), Happy class (12 children), and Kiss class (8 children). The children of the Rainbow class had multiple severe disabilities, and most children could not control their physical activities and relied on others to assist them with basic intellectual tasks. Most of the other four classes contained children with delayed development, some of them with moderate to mild retardation or with physical disabilities. The status of sensory perception, cognitive development, language development, psychological development, communication ability, self-care and social adaptation in each class are explained as follows.

The 13 young children in the Rainbow class had the following health statuses: two had severe disorders and cerebral palsy; one had limbs with involuntary muscle jumping and epilepsy symptoms; one used a hearing aid and had epilepsy symptoms; one had developmental retardation; one had infantile cerebral palsy (limb 
paralysis); one had microphthalmia in the left eye and no right eye; one had extremely severe disorders and epilepsy symptoms; one had moderate disorders, broad beans, infantile cerebral palsy (enlarged ventricles) and epilepsy symptoms; one was hypertonic; one had limited joint mobility; one had cerebral palsy; one had low muscle tone and 11th-pair chromosomal abnormalities; and one had extremely severe type 1 and type 7 disorders and no language abilities.

The Sweet class comprised13 young children with the following health statuses: one had autism and developmental retardation, slow brain development, and moderate mental retardation; two had mild mental impairment; two had language developmental retardation; one had no language ability; one had mild developmental retardation and required the use of orthopedic insoles; one had receptive/expressive mixed language development retardation; one had epilepsy and developmental retardation; one had congenital spina bifida and hydrocephalus; one had epilepsy and developmental retardation; one had congenital spina bifida with hydrocephalus; one had Down syndrome; one had a moderate mental disorder, high hyperopia, right eye amblyopia, and encephalitis; one would sometimes have allergic reactions to egg foods and exhibit redness around the lips.

The Beibei class comprised six young children with the following health statuses: four with developmental retardation; one was repulsed by unseen food and exhibited picky behavior regarding the consumption of meat; and one had hyperopia and hearing deficiency (20 $\mathrm{dB})$.

The Happy class comprised 12 young children with the following health statuses: one had brain damage and developmental disorders; three had epilepsy; one had infantile autism and mild mental retardation; one had an eating disorder and disliked all foods except those with a single, dominant taste; two had amblyopia and strabismus; one had serious eclipse behavior; two had good physical and mental condition; one had physical disorders.

The Kiss class comprised 12 young children with the following health statuses: One had visual impairment and PHPV permanent vitreous hyperplasia; one had developmental retardation with abnormal language development and autism; and six had developmental retardation.

In addition to the overall performance of the five classes, that of one young child in particular was assessed. She was a 6-year-old child in the Happy class named YunYun, whose disability category was developmental retardation. Her health conditions included amblyopia and strabismus, and her recovery after surgery was good. The study coincided with the waiting period for a doctor for postoperative evaluation, during which time it was noted that when drinking water, the child was vulnerable to choking. In terms of health, she had amblyopia and strabismus; these issues involved problems with visual sensory perception, which translated to poor performance on the right side of her body and resulted in uncoordinated bilateral integrated movements during gross motor movements. Other symptoms that were observed included excessive straightening of the chest and waist in the trunk posture, which led to muscle imbalance and loss of muscle control. In terms of communication, the child could use complex sentences to express key points of events or tell stories, and events in familiar contexts could be described in simple terms. Cognitively, she demonstrated an overall lack of attentiveness and high distractibility.

\subsection{Teaching Research Design and Teaching Material}

This study was based on two theories of instructional design: MET and Figurenotes. The teaching content was divided into six stages: The Hello Song and Attendance Song, music stories, music activities (incorporating multiple rhythms and matching instruments), soothing songs (played while children were lying on the floor to alter their emotional state), and goodbye songs. This teaching content was designed according to the development of children's abilities in each class and utilized the seven colors of Figurenotes (see Figure 1) as the main axis of activity development. This content, combined with designed musical elements, was used to cultivate the children's ability to process auditory, visual, and tactile stimuli. Through music therapy, the children could interact with music and produce spontaneous behaviors.



Figure 1. The seven colors of Figurenotes

The teaching design of this study emphasized formulating teaching goals according to the abilities and needs of the children in each class. The teaching goals are positioned in the three dimensions of communication, music, and activity ability of the children. The researchers recorded the performance of the children in each of the three dimensions and scored them according to their individual abilities. Each case was cross-recorded by three observers and supplemented by the teachers' observation records to conduct multiple data cross-comparisons and thus confirm the reliability and validity of the research objectivity. Finally, the observation records were used for integration and analysis.

The music story of the course was "Colorful Fairy 
Kingdom" [1]. Throughout the story, the children were taught to recognize the seven colors of Figurenotes and change the seven colors into seven different fairies. Each of the seven colors represented a different pitch and a different pattern to imitate and tap while following the instructor and adding rhythm. Through imitation and tapping, children learned different rhythm types. Musical instruments were used to deepen the children's impressions and cognition of colors and to develop their fine motor skills. In addition to the fairy spirits imitating and tapping in the story, we added four nursery rhymes, namely "Two Tigers," "London Bridge Is Falling Down," Mary Had a Little Lamb," and "When We Are Together." The children were permitted to operate the instruments and play. With the use of familiar nursery rhymes, children were more involved in the curriculum.

Music stories were presented in a variety of ways, such as by acting, using a story apron with hand puppets, and reading large books to foster the children's learning focus and interest, trigger their learning motivation, and use music as a medium in the curriculum. Music activities with a variety of musical elements, such as changing tempo, instruments of different sizes, and stop-and-go exercises, promotes the development of children's large and small muscles and encourages physical movement. Various materials were used to make multiple teaching aids to reduce the children's tactile sensitivity and enrich the content of the curriculum to stimulate their senses.

The MET teaching course added the Figurenotes teaching method, which allowed children with different symptoms to rehearse and partake in music performances to exhibit their learning results. The teaching period was 15 weeks with one30-minute session per week. The course was divided into phases: weeks $1-5$ were Phase I; weeks6-10 was Phase II; and weeks $11-15$ were Phase III. Researchers, observers, and preschool teachers made contributions. The researcher was the instructor, and three fourth-year college students assisted with recording teaching observation.

\subsection{Data Assessment and Evaluation}

The research data were primarily based on a qualitative narrative, supplemented by quantitative data. The qualitative data included the basic information of the children and the observation record of their target ability; the quantitative data were scored on a 5-point Likert scale. The scores used to represent the children's participation in musical activities were 1(never), 2(rarely), 3(sometimes), 4(often), 5(always). Observers entered the teaching location after training, and they used cross-observation to record the children's performance in class from an objective perspective. The observation form was designed by the researchers, and the observation items were divided into three categories: 1. communication ability; 2. action performance (physical movements); and 3. music.

\section{Results}

\subsection{Comprehensive Performance of All Children}

\subsubsection{Comprehensive Performance of the Rainbow Class}

At the beginning of the course, because of the reorganization of classes by the institution, young children needed to adapt to having new classmates, and some newer students were not familiar with the content of the course. One new student had bad memories of singing, so he cried frequently in the first and second phases of the study, but the crying situation was substantially ameliorated in the last phase.

The following observations were recorded regarding the three dimensions (communication ability, action performance, and music). In terms of communication ability, young children were unsuited to and unfamiliar with the curriculum in Phase I, and they did not respond to the directions of the instructor. By midterm (Phase II), the children had made substantial progress, from no response to being able to understand but requiring assistance to complete the tasks in the lesson. Children with higher function could understand the instructions and follow them independently in Phase III. In terms of physical movements, in the beginning phase of the curriculum, young children exhibited little response to the instructions because of their physical conditions and the inadequacy of the curriculum. By midterm, the children's physical functioning had greatly improved. Although they could not fully perform the correct movements, they could understand the movement instructions. Children with greater skill could understand the instructions and make the correct movements. In terms of music, students in the Rainbow class were unable to sing loudly like other children, but they could use body movements and instruments to express changes in music. In Phase I, the young children did not clearly understand the operation of musical instruments, but they could clap their hands to express changes in music. In Phases II and III, children with higher functioning could play percussion instruments on their own and also use their limbs to express changes in music. Other children could also use musical instruments, with some assistance, to express these changes. The Rainbow class included severely disabled children. After 15 weeks of the course, they had made meaningful progress, and their participation levels in the courses had also improved. A few children could be reminded to complete tasks independently. The group's overall performance is illustrated in Figure 2. 


\section{Comprehensive performance}

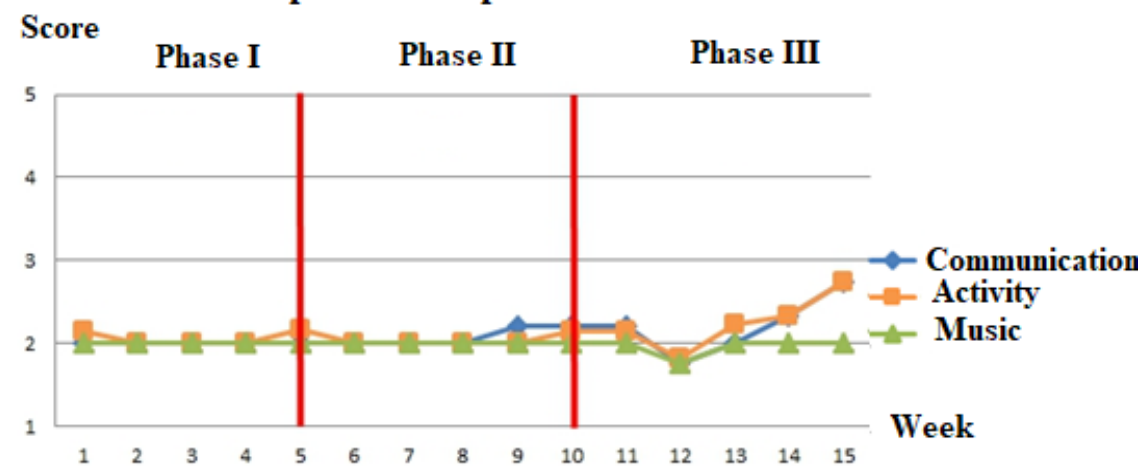

Figure 2. Comprehensive performance of the Rainbow class in three dimensions in the MET and Figurenotes teaching method

\section{Comprehensive performance}

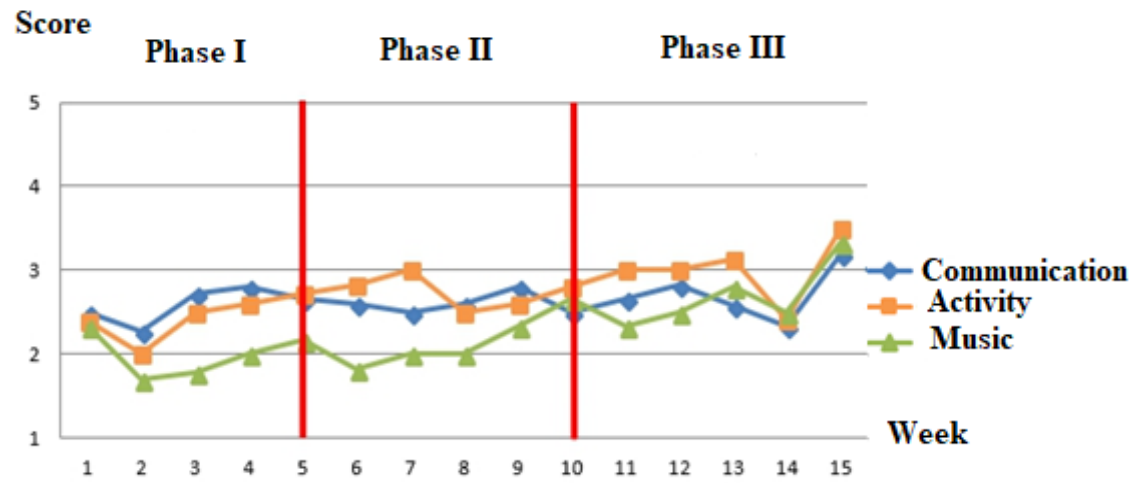

Figure 3. Comprehensive performance of the Sweet class in three dimensions in the MET and Figurenotes teaching method

\subsubsection{Comprehensive Performance of the Sweet Class}

The Figurenotes teaching method was added this semester, so children needed to adapt to the teaching model. At the beginning of the lesson, most of the children were emotionally agitated and unable to respond to instructions. After a few weeks of class, most children could adapt to the content of the curriculum. Their emotions were also more stable than in the earlier stage, although occasional help was needed to stabilize their emotions.

In all three dimensions at the beginning of the course, most young children were interested in the music story but could not respond to the directions given by the instructor. During music activities, some young children did not refrain from beating the musical instrument after receiving it. The mood of the whole class was more restless, and they could not listen to the instructions given by the teacher. In the later phase of the lesson, most young children were able to respond to the directions given by the instructor and could verbally answer questions in complete sentences. They were more able to listen to the instructions given in response to the hitting of instruments. Learning performance exhibited a downward trend in the later period because the children left to practice the graduation ensemble in the auditorium. Therefore, when the instructor gave directions, some children could not focus. Children in the Sweet class in this semester exhibited slight improvement in the last phase. The children could respond to individual instructions given by the instructor. In the early stage of the curriculum, the teaching assistant had to constantly remind the majority of the children to settle down. Later in the curriculum, some children required reminders from the faculty to secure the lesson. Each week's course content involved different instruments and rhythms, which encouraged the children to practice continuously. After repeated practice and learning every week, most children had made significant progress. The overall performance is illustrated in Figure 3. 


\section{Comprehensive performance}

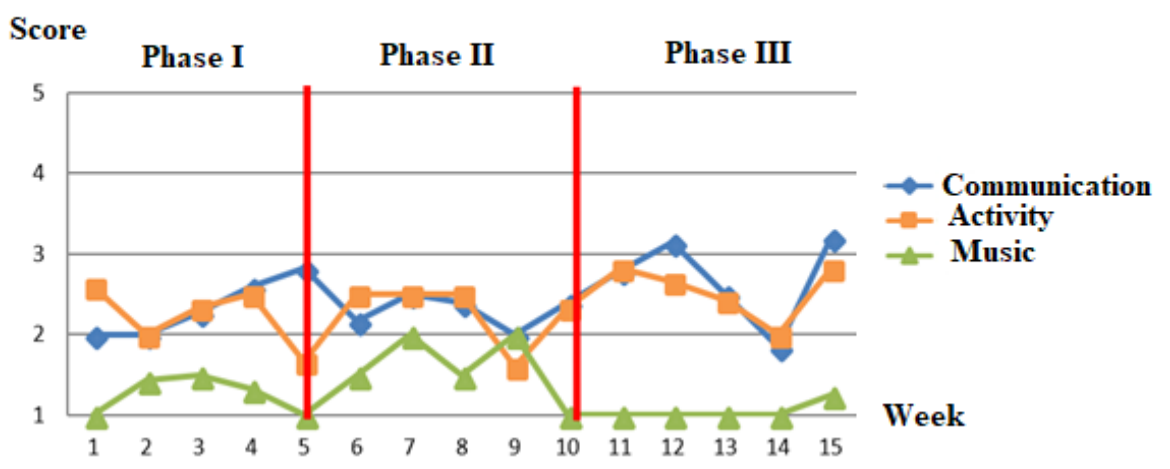

Figure 4. Comprehensive performance of the Beibei class in three dimensions in the MET and Figurenotes teaching method

\subsubsection{Comprehensive Performance of the Beibei Class}

At the beginning of the course, the class contained new students who were unfamiliar with the teaching staff. Many of these children felt anxious and cried. In terms of communication, these children demonstrated low participation in the course and emotional instability in the early stage. In the Hello Song and Attendance Song, most children needed reminders and assistance from helpers to complete the instructions given by the teaching staff. In the music story, only a few young children could respond to the teacher. After a few weeks of the course, the children's progress could be observed. Most of the children could follow the teacher's demonstrations and sing, and even children who were usually less responsive could participate and respond to the teacher. In the Goodbye Song, only a few children responded to the teacher in the early phase, but after a few weeks of the course, most children were able to wave their hands, say goodbye to the teacher, and speak according to the instructions. In terms of physical movements, at the beginning of the course, children were still adapting to the new teaching team. For the Hello Song, most children did not respond to the instructor; for the Attendance Songs, most children needed reminders and assistance to perform the movements, and only a few could respond to the teachers' questions. After midterm, most of the children were highly engaged and had demonstrated the ability to act independently or with assistance. Only a few young children followed the movements in the songs. By the middle of the lesson, one or two young children in the class were consistently learning and could follow the instructor's directions. Overall, compared with communication and physical movement performance, the music learning performance for this group was less satisfactory.

Throughout the entire course, the children gradually became familiar with the curriculum model, their participation in the class gradually increased, and their interactions with the teachers improved. When the content of the course changed, it was observed that young children did not exclude new musical instruments or fairies, and they could also participate in music stories. In music activities, they could manipulate musical instruments either autonomously or with assistance. The degree of participation was high. The results for this group suggest that through the MET teaching model, children can slowly develop and progress in subtle ways. The overall performance is illustrated in Figure 4.

\subsubsection{Comprehensive Performance of the Happy Class}

The comprehensive performance results from the combination of music education theory and the Figurenotes music course. In Phase I, most of the children were still adapting to the class and its structure. The children's reactions in class were to look at the teacher but not follow the teacher's actions and not respond as prompted. In the middle of the course, the "Two Tigers" song was introduced and repeatedly practiced. To determine which instruments the children were more responsive to, the teacher switched instruments in each class, using instruments such as the tambourine, sound brick, and xylophone. Sometimes children did not respond to specific instruments, were attracted to new instruments, or did not focus on the teacher. Consequently, the growth curve in the middle of the term was unstable. In the later stages of the course, the children gradually became familiar with the "Two Tigers" song, which the student could either perform or watch being demonstrated by the teacher. Most children took the initiative to participate in the activities, and the growth curve in the last phase exhibited a steady upward trend. In week 13, the first ensemble was performed, the class location was changed, and some classes were combined. Therefore, the children did not adapt immediately; consequently, the overall performance curve declined. The comprehensive performance trend of the Happy class in three dimensions is exhibited in Figure 5. 


\section{Comprehensive performance}

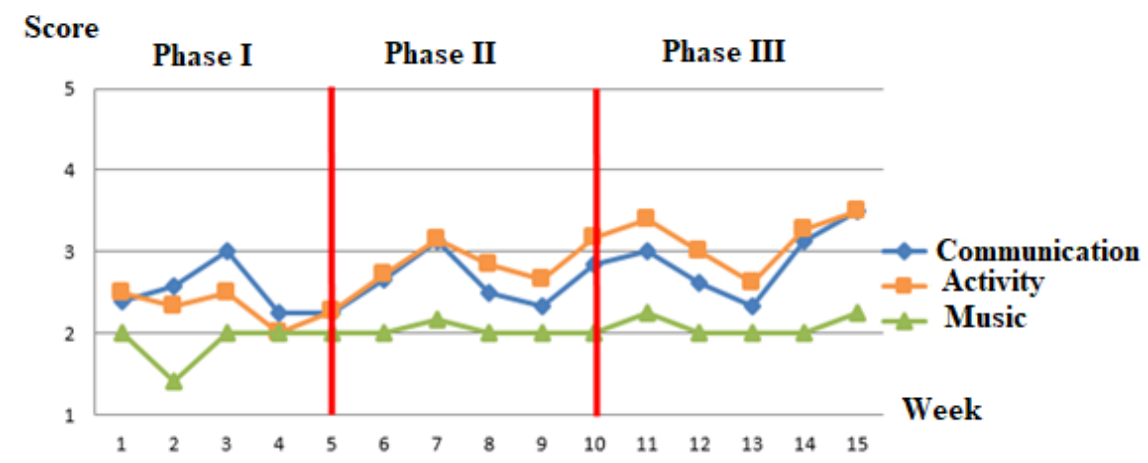

Figure 5. Comprehensive performance of the Happy class in three dimensions in the MET and Figurenotes teaching method

\section{Comprehensive performance}



Figure 6. Comprehensive performance of the Kiss class in three dimensions in the MET and Figurenotes teaching method

\subsubsection{Comprehensive performance of the Kiss class}

At the beginning of the course, some new students were unfamiliar with the material and would cry or refuse to participate in class. After a few weeks, the children's emotions stabilized, and they could respond to the content of the course. In terms of communication, the children's emotional instability was evident at the beginning of the lesson. Even if the teacher suggested a response, the children did not repeat it. They only silently watched the teacher. New fairy stories were added in the middle of the course; by this time, the children had gradually become familiar with the storyline and could respond to more open questions such as "Where is the fairy hiding?" by speaking or pointing. In terms of physical movement, young children who had not been familiar with the lesson mode could not follow the directions of the instructor to perform actions. In the later stage, it was observed that the children could clap their hands quickly or slowly according to the instructions. Only a few children needed assistance. At music story time, in the beginning, children only concentrated on listening to the story to find the fairy songs by themselves. During music activity time, different musical instruments were singled out to demonstrate their proper use; when the instructor directed the performance, the children could also tap or use the instrument with the assistant's prompt. Initially, the children did not sing or perform the actions, but by the middle of the lesson, children could clap or sing on their own. When the instructor gave new directions, the children could understand and follow them correctly. During the music activity, the children were unfamiliar with the songs and playing the instruments, and a few were reluctant to use the musical instruments. By the later phases, the children responded to the instructor's command to play the instruments. Young children with weaker ability could also hear the sound of the triangle, put an index finger on their mouths, and stop tapping. The children clearly achieved substantial progress in music learning.

The performance curve of the Kiss class exhibited a steady increase in Phase III, indicating that the children's performance in the latter part of the course had improved greatly. The MET course can indeed help young children improve the development of multiple abilities. The comprehensive performance trend of the Kiss class in three dimensions is shown in Figure 6.

\subsection{YunYun's Performance in Three Aspects}

\subsubsection{Communication ability}

In the early part of the course, YunYun was still adapting to the new curriculum and the classmates in her new group, which prevented her from understanding and 
keeping up with the teacher's instructions. However, when the instructor took the red fairy out and clapped with her, YunYun was able to give a "high-five" to the red fairy. In the Goodbye Song, when the instructor said goodbye to YunYun, she understood the instructions and waved to the instructor and said, "goodbye." In the middle of the course, YunYun gradually became familiar with the course content and began to respond to the instructors more actively. By the end of the course, YunYun was very familiar with the course content and could interact well with the instructors.

In week 15, when the instructor gave simultaneous clapping and stepping instructions, YunYun could understand and proactively respond to the instructor by making clapping and stepping motions; when the instructor signaled to be quiet, YunYun took the initiative to make a "shh" action in response; when the instructor gave singing and tapping instructions, Yun Yun could imitate the correct rhythm; when the teacher added spoken language, YunYun could understand and correctly repeat the lyrics. YunYun's increased communication ability with the MET and Figurenotes music teaching method is shown in Figure 7.

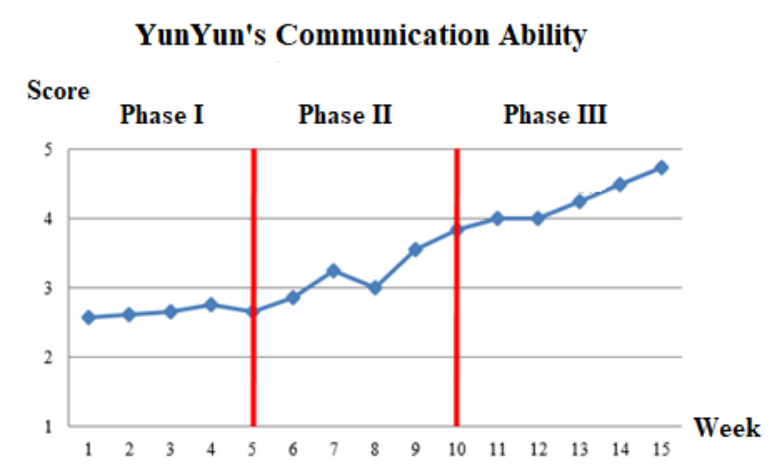

Figure 7. YunYun's communication ability with the MET and Figurenotes teaching method

\subsubsection{Activity performance}

When the instructor asked YunYun to distinguish between red and black in the roll song of the first week, YunYun could understand the instructions and correctly distinguish between red and black and was able to ring the bell. By midterm, YunYun had gradually become familiar with the content of the course and began to actively respond to the instructor. However, in week 8, when a new musical instrument (piano) was added, because she was being exposed to this instrument for the first time, she could not respond correctly. By phase III, YunYun could actively complete the instructed actions and could follow the instructor to clap correctly. The trend in her participation is illustrated in Figure 8.

\section{YunYun's Activity Performance}

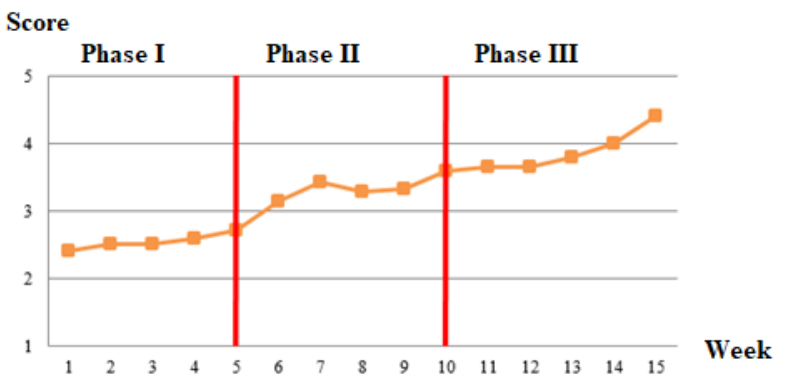

Figure 8. YunYun's participation under the MET and Figurenotes teaching method

\subsubsection{Music performance}

With YunYun's first exposure to the Figurenotes teaching method, she did not seem to understand or respond to prompts during the music activity. By the end of the first week, she could clap her hands in response to the instructor but she could not correctly imitate the instructor's clapping. By the sixth week, when the instructor sang the "Hello Song," YunYun could sing along. During the music story, when the instructor gave the command to imitate and flap, YunYun could not correctly imitate the teacher's flapping or clapping of the rhythm, but she could repeat a mantra. When the instructor gave "Do" and "Sol" commands, YunYun was unable to imitate the instructor to sing the rhythm correctly. During the music activities in the later stages of the course, YunYun could sing" Two Tigers" with the instructor, and she could also sing the Goodbye Song. When the instructor directed her, YunYun could play the metallophone correctly, and when the instructor gave instructions for body movements (shaking), YunYun also could understand and shake her body in response. YunYun no longer needed the instructor to remind her how to play the metallophone actively and correctly. The trend in her music learning performance is displayed in Figure 9.

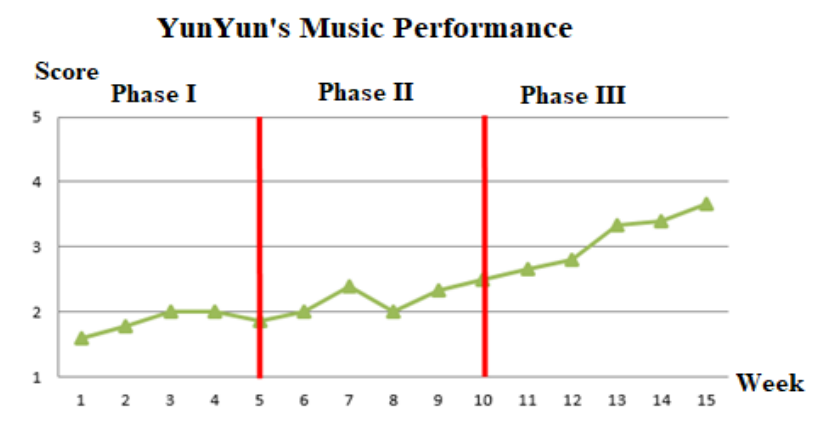

Figure 9. YunYun's music performance under the MET and Figurenotes teaching method 


\section{Discussion}

Like all children, young children with special needs should have the opportunity to listen to music, sing, and play simple instruments in the classroom [13]. MET and Figurenotes teaching strategies were combined in the present study to introduce music to children aged 1-6 years with special needs with the aim of promoting their physical and mental development through music. The physical movements of children with multiple disabilities in learning activities were significantly affected by physical impairment [14]. The results of this study revealed that young children with special needs were interested in music and that overall, after approximately six lessons (30 minutes per lesson), most young children could interact with each other and with the instructors after attending music lessons. Their communication ability, physical activity, and music experience all tended to grow. The findings of this study corroborate arguments presented in related research.

Color was used in the present study to guide the music learning of young children according to Figurenotes, which was developed by Kaarlo Uusitalo in 1996 and 2011. The method was first used in music therapy with the main objective of developing a simple notation to allow immediate enjoyment during the first lesson. YunYun's case results reinforce the effectiveness of the approach. Although she was older than the other students and the severity of her impairment was relatively low, she made remarkable progress after receiving music education based on the Figurenotes teaching method. One child in the Rainbow class had relatively severe impairments but exhibited a clear improvement trend by the end of the course (Phase III). The Figurenotes teaching method was clearly of great help to young children with special needs. [15] studied the effect of applying the Figurenotes method to teach young children with special needs and found that in the bodily-kinesthetic domain, Figurenotes aided the development of motor coordination. It also enhanced the students' self-esteem and motivation through positive learning experiences. At the interpersonal level, the Figurenotes method provided substantial opportunities for group activities. Figurenotes seemed to make learning easier and provided teachers with richer opportunities. The positive results of this experimental teaching study are consistent with previous research findings.

Among young children with special needs, their willingness to learn and motivation can increase through multisensory visual, auditory, and tactile stimulation [16, 17]. Young children with multiple disorders encounter more setbacks and stress due to their physical and functional deficits and activity restrictions, which can create challenges in learning and adaptation. This study was based on MET activities combined with the Figurenotes teaching method, which helped young children with multiple disabilities to learn in a natural context with multisensory stimulation.

\section{Conclusions}

In summary, the use of MET and the Figurenotes teaching method demonstrated meaningful and positive effects as a therapy for children with special needs. This teaching method may be suitable not only for children but also adults; moreover, it also demonstrates potential as an effective therapy and teaching device for young children with special needs. It is expected that the results of this study will be used by special education researchers and workers in the future to provide a different kind of education and treatment for children with special needs.

\section{REFERENCES}

[1] Lee, L. Music, a wonderful window for young children's learning. The Learning Teacher Magazine, 2012, 3 (2), 6-7.

[2] WFMT. What is music therapy? Retrived from https://www.wfmt.info/wfmt-new-home/about-wfmt/. 2011.

[3] Storr, A. Music and the mind. London: Harper Collins. 1997.

[4] Schwartz, E. Music therapy, and early childhood: A developmental approach. Gilsum, NH: Barcelona Publishers.2008.

[5] Schulberg, C.H. The music therapy sourcebook: A collection of activities categorized and analyzed. NY: Human Sciences Press. 1986.

[6] Thompson, K. Music for every child: Education of handicapped learners. Music Educators Journal, 1982, $68(8), 25-28$.

[7] Gfeller, K. Musical components and styles preferred by young adults for aerobic fitness activities. Journal of Music Therapy, 2008, 25(1), 28-43.

[8] McCord, K. A., \& Lee, L. C. Using music technology with young children with autism: Two case studies. Paper presented at the 18th ISME Commission Seminar on Music in Special Education, Music Therapy, and Music Medicine, Thessaloniki, Greece.2012.

[9] Kaikkonen, M., \& Kivijärvi, S. Interaction creates learning: Engaging learners with special educational needs through Orff-Schulwerk. Approaches: Music Therapy \& Special Music Education, 2013, 5(2), 132-137.

[10] Kivijärvi, S. Project disabled people as musicians: A systemic approach. Procedia-Social and Behavioral Sciences, 2012, 45, 416-427.

[11] Laes, T., \& Westerlund, H. Performing disability in music teacher education: Moving beyond inclusion through expanded professionalism. International Journal of Music Education, 2017, 1-13. 
[12] Ruokonen, I., Pollari, S., Kaikkonen, M., \& Ruismäki, H. The Resonaari Special Music Centre as the Developer of Special Music Education between 1995-2010. Procedia Social and Behavioral Sciences, 2012, 45, $401-406$.

[13] Darrow, A.-A. Early Childhood Special Music Education. General Music Today, 2011, 24(2) 28-30.

[14] Ostensjo, S., Carlberg, E. B., \&Vollestad, N.K. Everyday functioning in young children with cerebral palsy: Functional skills, caregiver assistance, and modifications of the environment. Developmental Medicine and Child Neurology, 2003, 45(9), 603-612.

[15] Vikman, K. Dimensions of the Figure notes-method in the first years of piano-playing: Action research with different target groups. Research Reports, 2001, 177. Department of Education. University of Helsinki.

[16] Lee, L., \& Lin, S. Investigating the impact of music activities incorporating Sound beam technology on children with multiple disabilities. Paper presented at the 22st European Teacher Education Network (ETEN) Conference. Portugal, Coimbra.2012.

[17] Lee, L., \& Lin, S. Evaluating the use of music with teaching aids in a multisensory environment on developing children with disabilities positive emotions and communication skills. In J. Portela, I. Vale, F. Huckaby, \& G. Bieger (Eds.), The Proceeding of the23rd Annual Conference of the European Teacher Education Network (ETEN) (pp. 143-162). Hasselt, Belgium.2013. 